
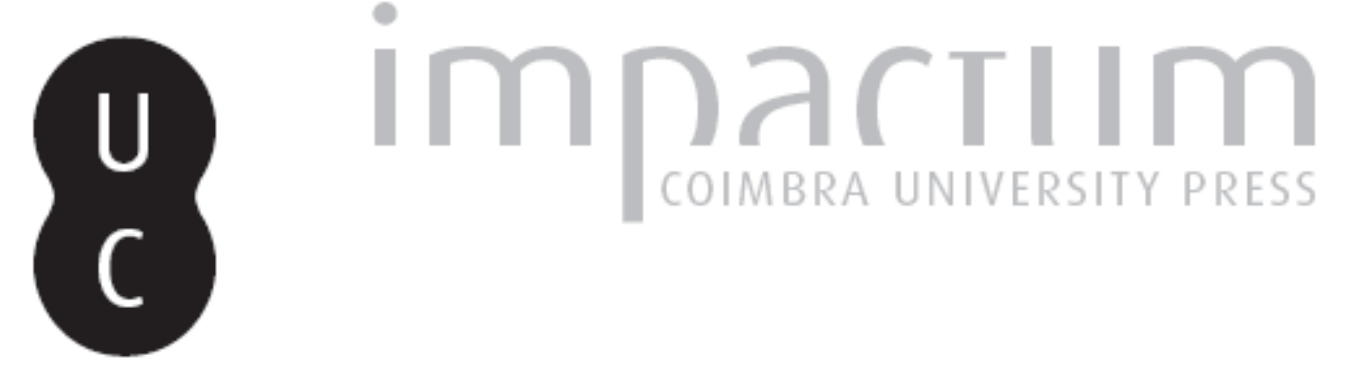

\title{
A Geografia dos incêndios em espaços silvestres de montanha, objecto de estudo numa tese de doutoramento em Geografia Física e Estudos Ambientais
}

Autor(es): Lourenço, Luciano

Publicado por: Associação Portuguesa de Riscos, Prevenção e Segurança

URL

persistente:

URI:http://hdl.handle.net/10316.2/36208

DOI:

DOI:http://dx.doi.org/10.14195/1647-7723_15_13

Accessed : $\quad$ 26-Apr-2023 13:16:50

A navegação consulta e descarregamento dos títulos inseridos nas Bibliotecas Digitais UC Digitalis, UC Pombalina e UC Impactum, pressupõem a aceitação plena e sem reservas dos Termos e Condições de Uso destas Bibliotecas Digitais, disponíveis em https://digitalis.uc.pt/pt-pt/termos.

Conforme exposto nos referidos Termos e Condições de Uso, o descarregamento de títulos de acesso restrito requer uma licença válida de autorização devendo o utilizador aceder ao(s) documento(s) a partir de um endereço de IP da instituição detentora da supramencionada licença.

Ao utilizador é apenas permitido o descarregamento para uso pessoal, pelo que o emprego do(s) título(s) descarregado(s) para outro fim, designadamente comercial, carece de autorização do respetivo autor ou editor da obra.

Na medida em que todas as obras da UC Digitalis se encontram protegidas pelo Código do Direito de Autor e Direitos Conexos e demais legislação aplicável, toda a cópia, parcial ou total, deste documento, nos casos em que é legalmente admitida, deverá conter ou fazer-se acompanhar por este aviso.

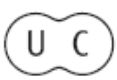




\section{territorium}

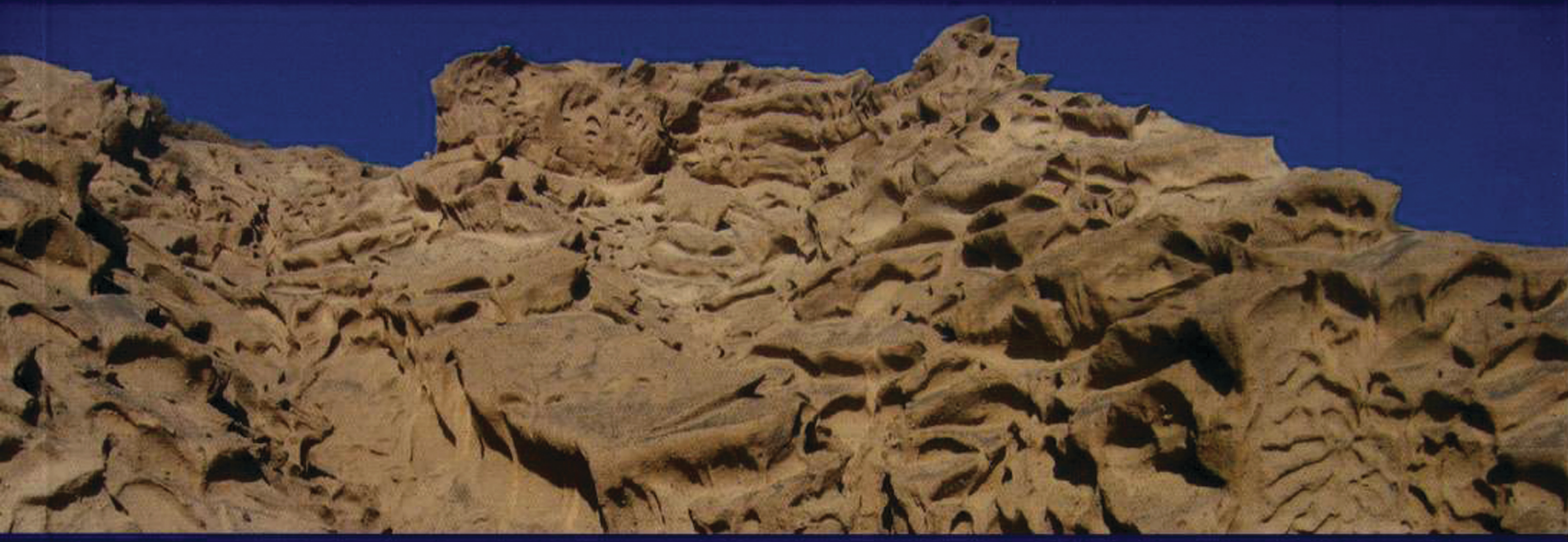

15

Revista da Associação Portuguesa de Riscos, Prevenção e Segurança 2008 


\section{A Geografia dos Incêndios em Espaços Silvestres de Montanha, objecto de estudo numa tese de doutoramento em Geografía Física e Estudos Ambientais}

Luciano Lourenço

António José Bento Gavaryus escolheu a Geografia dos Incêndios em Espaços Silvestres de Montanha ` O caso da Serra da Cabreira como tema da sua dissertação de doutoramento, a qual foi discutida em provas públicas, no Instituto de Ciências Sociais da Universidade do Minho, no dia 11 de Maio de 2007.

Esta tese, na sua versão impressa, distribui-se por 437 páginas de texto, acrescidas de mais 150 páginas de Anexos. Está profusamente ilustrada e documentada, quer através das 148 figuras e 20 fotografias, todas elas a cores, quer por meio de 60 tabelas, que, de modo fácil, possibilitam aceder aos diversos elementos quantitativos, os quais, no seu conjunto, permitem dar, assim, maior precisão à escrita.

Após os agradecimentos, que ocupam três páginas, seguem-se os resumos, em português e inglês, os índices (geral, de figuras, de fotografias e de tabelas) e uma listagem de quatro páginas com as siglas e as abreviaturas usadas no texto, o que, no conjunto, ocupa as 39 páginas iniciais.

Depois, na introdução, páginas 41 a 74, procura justificar a razão de ser deste trabalho, define o tema e os objectivos, apresenta a metodologia e as ferramentas utilizadas, faz uma apresentação crítica dos dados, dando a conhecer algumas das dificuldades sentidas na sua dbtenção ou, atémesmo, a impossibilidade de acesso a alguns deles e questionando sobre a qualidade de outros, faz uma abordagem às questões terminológicas e termina com o modo como organizou a tese, contextualizando o enquadramento das duas partes en que esta se divide.

A primeira delas, dedicada aos "espaças silvestres de montanha", é, no dizer de António Benro, "de cariz teórico, resulta de uma exaustiva revisão bibliográfica e visa estabelecer o 'estadb da arte', sobre os espaços silvestres em áreas montanhosas" . Subdivide-a em três capítulos, respectivamente dedicados aos espaços silvestres montanhosos, aos que dedica 12 p., aos espaços silvestres em Portugal, que desenvolve ao longo de 73 p. , e ao Noroeste Português, que ocupa 51 páginas.

Por sua vez, a segunda parte da tese, que trata da "geografia dos incêndios florestais", distribui-se por dois capítulos, respectivamente, sobre a geografia e incêndios florestais, que trata em 36

p., e as incêndios florestais nos espaças silvestres de áreas montanhosas, que é o mais extenso, ocupando 132 páginas.

Termina com catorze páginas de notas conclusivas e 30 de bibliografia, distribuídas por 12 de obras citadas, 9 de obras consultadas, 1 de fontes cartográficas, 3 de outras fontes e 1 de sites, além das 150 páginas, antes mencionadas, que agnupam os seis Anexos seguintes:

I- Extractos do Código Penal Português de 1982, 1986 e 1995;

II- Festas e Romarias nos concelhos de Cabeceiras de Basto e de Vieira do Minho;

III- Codificação e Definição das Categorias das Causas dos Incêndios Florestais (DGRF), ilustradas com 9 fotografias;

IV- Legislação florestal em Portugal continental (1901-2006) ;

V - Caminhos florestais. São apresentados quatro exemplos e 16 fotografias de trabalhos de abertura e pavimentação;

VI- Autos de notícia, autos de ocorrência e fichas individuais do fogo (resumo), que constituemum verdadeiro repositório de informação, adnirável sobretudo por ainda não existirem as novas tecnologias e, mesmo assim, muitas dessas fichas são de um detalhe que hoje é impensável.

A primeira parte da tese começa com o capítulo dedicado aos espaços silvestres montanhosos, de natureza introdutória, passando, no segundo capítulo, à caracterização dos espaços silvestres em Portugal, o qual é sustentado numa sólida fundamentação histórica, pelo que merece ser destacado, uma vez que a sua leitura permite ter uma perfeita percepção da evolução histórica sobre os sucessivos ciclos das políticas florestais.

Depois, no terceiro capítulo, passa, à caracterização do Noroeste português, começando pelos aspectos gerais e, descendo de escala de análise, descreve, a seguir, as espacas silvestres de montanha existentes nesse território, para, por fim, continuandb a descer na escala de análise, se centrar na sua área específica de estudb, a serra da Cabreira. De certo moob, tratase de capítulo de transição, em que se prepara o leitor para a segunda parte do trabalho, dedicada à caracterização das incêndios florestais nos espaços 
silvestres de áreas montanhosas e, emparticular, aos incêndios florestais na serra da cabreira.

Esta segunda parte é, sem qualquer sombra de dúvida, o corpo central da dissertação de doutoramento. Nela está espelhado, de forma muito clara, o esforço conjugado e continuado de entidades e pessoas anónimas (engenheiros, técnicas, guardas florestais, capatazes, ... homens emulheres, simples jomaleiros) que foi necessário desenvolver no dia a dia, mês a mês, ano após ano, para transformar uma serra "careca" em floresta produtiva. Esse esforço, está bempatente e profusamente documentado, suportado em tabelas e ilustrado com figuras e fotografias que patenteiam bem a grandeza de espírito e a visão das obreiros dessa "construção florestal".

Só por isso esta tese estaria justificada, mas vai muito mais longe, além de que constitui uma justa e merecida homenagem a esse esforço, por vezes tão criticado quanto desconhecido, que, não há dúvida, permitiu mudar, com escassos meios técnicos, sublinhe-se, não só a face da serra da Cabreira, mas também a de tantas outras serras interiores edunas litorais.

Em contrapartida, como António Bento comprova, à medida que passaram a abundar soluções tecnicamente mais evoluídas, foi-se avançando na "desconstrução florestal". E esta numca poderá ser atribuída exclusivamente aos incêndios florestais!

Com efeito, como o autor bem documenta e ilustra, também nos anos sessenta, ainda em plena fase de "construção", se registavam incêndios florestais, alguns deles com certa gravidade, só que eram encarados e atacados numa perspectiva diferente daquela que se lhes seguiu, sobretudo a partir do início dos anos oitenta do século passado, após a publicação do Decreto Regulamentar n. 55/81, de 18 de Dezembro.

Apesar de nos últimos anos, muito se ter escrito sobre incêndios florestais, como o António Bento bem demonstra na bibliografia utilizada, consegue analisar, no subcapítulo dedicado aos incêndios florestais na Serra da Cabreira, alguns assuntos inéditos ou muito raramente abordados como, por exemplo, as causas dos incêndios ocorridos desde finais dos anos 50 ou princípios dos anos sessenta até meados de oitenta, bem como os meios utilizadas no conbate a incêndios florestais durante esse período de tempo (p. 329 a 343) ou, ainda, a caracterização dos arguidos em crimes de "incêndio posto em floresta, mata, arvoredo ou seara" (p. 348 a 353), os quais constituem, claramente, um importante contributo não só para a caracterização da respectiva evolução, mas também para a explicação do gradual aumento do risco de incêndio florestal que, desde então, se temvinab a registar.

No que toca ao risco de incêndio florestal salienta (p. 384) a importância do "histórico das áreas ardidas como ponto de partida para selecção e valoração dos factores biofísicos e humanos intervenientes nos incêndios ocorridas" apontando a reincidência como um dos factores que, en termos médios, ajuda a caracterizar o risco.

Termina o capítulo dedicado aos incêndios florestais nos espaços silvestres de áreas montanhosas com uma proposta de modelação do risco de incêndio. Trata-se, sem dúvida, de um primeiro ensaio metodológico, mas que, naturalmente, carece de grande aprofundamento e de maior desenvolvimento, uma vez que modelar as riscos naturais e antrópicos (e, sobretudb, estes!) não é tarefa fácil, para que se obtenha não só um modelo credível, mas também e, principalmente, exequível, ou seja, umproduto eficiente e eficaz, a ser usado como verdadeiro instrumento (e não apenas como mais um mero elemento decorativo) de ajuda à decisão, tanto em termos de prevenção como de combate a incêndios florestais.

Chegados ao fim, resta-me dizer que a tese do António Bevro, não sendo um estudo exaustivo e maçador - bem pelo contrário! - , é susceptível de atrair os leitores, pois, trata-se de uma apresentação multifacetada sobre um tema actual e que relata a evolução de um espaço que, certamente, despertará o encanto e a curiosidade para uma visita que, in loco, permitirá observar muitos dos aspectos apresentados nesta dissertação.

A Geografia dos Incêndios em Espaças Silvestres de Montanha - O caso da Serra da Cabreira, de António Bento Govasulss, é, pois, uma obra cuja leitura se recomenda não só aos que gostam da Geografia Física de Portugal, mas também àqueles que se dedicam aos Estudos Ambientais e, ainda, a todos quantos se preocupam com as Riscos Dendrocaustológicas, tanto mais que está disponível em https:// repositorium.solum.uminho.pt/handle/1822/6508 